\title{
Erratum to: Histopathological, Molecular, and Genetic Profile of Hereditary Diffuse Gastric Cancer: Current Knowledge and Challenges for the Future
}

\author{
Rachel S. van der Post, Irene Gullo, Carla Oliveira, Laura H. Tang, \\ Heike I. Grabsch, Maria O’Donovan, Rebecca C. Fitzgerald, Han van \\ Krieken, and Fátima Carneiro
}

Erratum to Chapter 18 in M. Jansen, N.A. Wright (eds.), Stem Cells, Pre-neoplasia, and Early Cancer of the Upper Gastrointestinal Tract, Advances in Experimental Medicine and Biology 908, DOI 10.1007/978-3-319-41388-4_18

(C) Springer International Publishing Switzerland 2016

In the original version of this chapter, the following statement was omitted on the first page

"The first two authors (Rachel S. van der Post and Irene Gullo) contributed equally to the writing of the chapter". 